Trab. Ling. Aplic., Campinas, 50(1): 189-204, Jan./Jun. 2011

\title{
MOBILIZAÇÃO DE PRÁTICAS LETRADAS NA PRODUÇÃO DE PALESTRAS: UMA ANÁLISE DE REDAÇÕES DE VESTIBULAR
}

\author{
MOBILIZATION OF LITERATE PRACTICES IN THE PRODUCTION OF \\ TALKS: AN ANALYSIS OF UNIVERSITY ENTRANCE EXAM ESSAYS
}

\author{
ELIZABETH MARIA DA SILVA* \\ DENISE LINO DE ARAÚJO**
}

\begin{abstract}
RESUMO: Tendo em vista que, nas provas de redação aplicadas pela Universidade Federal de Campina Grande, está sendo exigida a escrita de um gênero textual (artigo de opinião e relato de experiência, UFCG 2005; depoimento e carta denúncia, UFCG 2006; palestra e resenha, UFCG 2007; análise comparativa de dois poemas e reportagem, UFCG 2008) e que cada candidato que se submete a tal exame tem um histórico de letramento (doravante HL) particular, este artigo tem dois objetivos: (1) averiguar as práticas letradas requeridas na produção da palestra proposta na prova de redação aplicada no vestibular da UFCG em 2007 e (2) analisar as associações entre a mobilização de práticas letradas nas palestras e o histórico de letramento dos candidatos. Trata-se de uma pesquisa descritivo-interpretativa de cunho qualitativo, cujo corpus foi constituído por quatro conjuntos de dados, a saber: (1) prova de redação aplicada no vestibular; (2) amostragem de palestras produzidas; (3) questionário socioeconômico e cultural respondido pelos candidatos e (4) entrevista semi-estruturada realizada com os mesmos. Os dados, analisados com base nos estudos contemporâneos sobre letramento (cf. BARTON \& HAMILTON, 2000; GEE, 2000; MEY, 2001; BAZERMAN, 2007), sinalizam, de um lado, a presença de multiletramento na prova e, por outro lado, indicam que o HL dos candidatos parece ser fator decisivo para a mobilização de práticas letradas na redação. Os candidatos que demonstraram conhecer as práticas exigidas no vestibular provavelmente tinham familiaridade com eventos de letramento, cujas práticas eram semelhantes às exigidas no evento escolhido no exame, já aqueles que as não atenderam de modo adequado parece que tinham mais experiência com o letramento escolar. Assim, os resultados levam-nos a concluir que práticas escolares parecem não ser suficientes para que os vestibulandos demonstrem as práticas multiletradas exigidas na prova. Palavras-chave: palestras, práticas letradas, histórico de letramento.
\end{abstract}

ABSTRACT: Having in mind that, in the composition tests applied by the Federal University of Campina Grande (UFCG), it is required the writing of a textual genre (opinion article and experience report, UFCG 2005; testimony and report letter, UFCG 2006; review and talk, UFCG 2007; comparative analysis of the two poems and documentary, UFCG 2008) and that each candidate who takes the exam has a particular literacy history (LH), this article has two objectives: (1) to check the literacy practices required in the writing of the talk proposed in the composition test applied at the college entrance exams for the Federal University of Campina Grande, in the year 2007 and (2) to analyse the relationship between the mobilization of literacy practices, both in the talks and in the candidates' LH. This research is descriptive-interpretative, of qualitative nature, whose corpus was composed of four data sets, namely: (1) a composition test applied at the college entrance exams, held at the Federal University of Campina Grande in 2007; (2) samples of talks produced during these exams; (3) a socioeconomic and cultural questionnaire answered by the candidates, and (4) a semi-structured interview done with them. The data, analysed on the basis of present-day studies on literacy (cf. BARTON \& HAMILTON, 2000; GEE, 2000; MEY, 2001; BAZERMAN, 2007), show the presence of multiliteracy in the test, and also indicate

"UFCG, Campina Grande, (PB), Brasil. professoraelizabethsilva@gmail.com

** UFCG, Campina Grande, (PB), Brasil. linodenise@yahoo.com.br 
DA SILVA e ARAÚJO - Mobilização de práticas letradas na produção...

that the candidates' LH seems to be a decisive factor for the mobilization of literacy practices in the writing of talks. The candidates who demonstrated the practices required by the college entrance examination were probably familiar with literacy events whose practices were similar to those required by the event present in the exam paper, whereas those who did not perform them well may have had more experience with school literacy. Thus, the results have shown that school practices appear to be insufficient for the candidates to demonstrate the multiliterate practices required by the exam.

Keywords: talks, literate practices, literacy history.

\section{INTRODUÇÃO}

Na maioria dos vestibulares realizados nos estados brasileiros, a dissertação escolar é solicitada nas provas de redação (cf. LIMBERT, 2006; THEREZO, 2002; COSTA VAL, 1999; PÉCORA, 1986; LEMOS, 1984; ROCCO, 1981). No entanto, em algumas universidades, a exemplo da Universidade Federal de Campina Grande (UFCG), vem sendo exigida, nessa prova, a produção de gêneros textuais diversos - artigo de opinião e relato de experiência (UFCG 2005); depoimento e carta denúncia (UFCG 2006); resenha e palestra (UFCG 2007), reportagem e análise comparativa de dois poemas (UFCG 2008); abaixo-assinado e artigo jornalístico (UFCG 2009).

Tendo em vista o novo direcionamento que foi dado pela UFCG à prova de redação e partindo do pressuposto de que as práticas letradas demonstradas pelo sujeito em um determinado evento parecem ser influenciadas pelo seu histórico de letramento (doravante $\mathrm{HL}$ ), pela sua experiência com práticas de leitura e de escrita, desenvolvemos uma pesquisa de mestrado norteada pela seguinte questão: que correlação pode ser estabelecida entre as práticas demonstradas pelos candidatos que produziram a redação nos vestibulares aplicados pela UFCG em 2007 e o seu HL? Neste artigo, focalizaremos a produção de palestras, um dos gêneros textuais solicitados em tal prova, mais especificamente aquelas nas quais os candidatos atenderam às práticas requeridas nesse evento ${ }^{1}$. Para isso, traçamos dois objetivos:

1. Averiguar as práticas letradas requeridas na produção da palestra proposta na prova de redação aplicada no vestibular especial ${ }^{2}$ da UFCG em 2007;

2. Analisar as associações entre a mobilização de práticas letradas nas palestras e o histórico de letramento dos candidatos.

Com vistas a atingir os objetivos acima elencados, realizamos uma pesquisa de natureza descritivo-interpretativa, (cf. ANDRÉ, 1995), na qual triangulamos informações provenientes de quatro conjuntos de dados, a saber: (1) prova de redação aplicada pela UFCG em 2007 no vestibular especial; (2) amostragem de palestras produzidas nesse vestibular, nas quais os candidatos atenderam às praticas letradas requeridas na prova; (3)

\footnotetext{
${ }^{1}$ Cabe esclarecer que, na dissertação de Silva (2009), foi analisada uma amostragem tanto dessas palestras, em que os candidatos atenderam às práticas letradas requeridas na prova, quanto de palestras em que não houve tal atendimento. Considerando as dimensões deste artigo, optamos por apresentar e analisar dois exemplos representativos da primeira categoria referida.

${ }^{2} \mathrm{O}$ vestibular especial é realizado no meio do ano. Nesse vestibular, são abertas inscrições para um número menor de cursos, os quais são oferecidos nos campi da UFCG localizados em cidades circunvizinhas a Campina Grande.
} 
questionário sócio-econômico e cultural elaborado e aplicado pela Comissão de Processos Vestibulares (COMPROV); (4) entrevista realizada pela pesquisadora com os candidatos.

Quanto à organização do presente artigo, o dividimos em cinco partes. Na primeira, apresentamos esta introdução; na segunda, explicitamos os princípios teóricos adotados; na terceira etapa, analisamos os dados; na quarta, tecemos as considerações finais e, por fim, na quinta e última parte, listamos as referências bibliográficas citadas ao longo do texto.

\section{FUNDAMENTOS TEÓRICOS}

Neste item, apresentamos os principais fundamentos teóricos que apoiarão a análise dos dados, a saber - perspectiva crítica do letramento e conceitos associados a essa perspectiva como o de agência, eventos e práticas.

\subsection{Letramento: um fenômeno plural}

Quando realizamos pesquisas fundamentadas teoricamente nos estudos sobre letramento, pelo menos duas concepções são evocadas, a autônoma e a ideológica(STREET, 1984), esta recentemente ampliada e denominada de crítica (BARTON \& HAMILTON, 2000 e GEE, 2000). Na primeira, pressupõe-se que há apenas uma forma de conceber o letramento, sendo essa forma caracterizada pela supremacia da modalidade escrita, que é vista como um produto completo em si mesmo, cuja interpretação é determinada pelo funcionamento/articulação dos elementos internos do texto. Dessa forma, o letramento é pensado como atividade única, universal, invariável e singular, visto que é a mesma, seja qual for a situação comunicativa em que figurar.

Já na segunda concepção, a ideológica, aqui denominada de crítica, estudiosos tais como Scribner \& Cole (1981), Heath (1983), Street (1984), Barton \& Hamilton (2000), Gee (2000) e Vóvio \& Souza (2005) começaram a defender a tese, com a qual concordamos e adotamos no presente trabalho, de que a leitura e a escrita, interligadas à ideologia e ao contexto sócio-histórico em que aparecem, são atividades humanas complexas, intimamente relacionadas às pessoas e aos lugares onde são utilizadas. Isso nos permite dizer que os usos e as funções do letramento modificam-se a cada agência letrada na qual são observados.

Essas agências letradas dizem respeito às áreas da vida (casa, trabalho, escola, igreja etc.) dos sujeitos, as quais estão associadas a diferentes letramentos - escolar, acadêmico, midiático, familiar, político, religioso, profissional, entre outros. Nessas agências, aparecem eventos de letramento, que, por sua vez, requisitam determinadas práticas letradas.

Barton \& Hamilton (2000), Marcuschi (2001), Kleiman (2001), Lopes (2006), esses quatro ancorados naqueles, defendem que os eventos de letramento são situações comunicativas mediadas por textos escritos, já que, para ser um evento, não é necessária a presença de um texto escrito graficamente, mas a retomada, pela modalidade oral, da ideia de um determinado texto. As aulas expositivo-dialogadas, ministradas pelos professores, por exemplo, são eventos, uma vez que o discurso do professor, assim como o do aluno 
estão pautados em experiências de leitura, no conhecimento de mundo que ambos têm quanto ao tema focalizado na aula.

Já as práticas letradas são definidas por Barton \& Hamilton (2000) como sendo maneiras culturais de como as pessoas usam a língua escrita na sua vida. Entretanto, não é permitido às pessoas usá-la da forma que quiseram, quando, onde e com quem preferirem. As práticas são formadas por regras sociais que regulam o uso e a distribuição dos textos, prescrevendo quem pode produzir ou ter acesso aos mesmos. Tais regras foram constituídas pelas agências de letramento. Logo, cada sujeito demonstra determinadas práticas conforme a agência da qual ele participa, haja vista que as práticas letradas articulam as atividades de leitura e escrita às estruturas sociais em que elas são embutidas e que ajudam a formar (cf. BARTON \& HAMILTON, 2000; MARCUSCHI, 2001). Acreditamos que a ideia relativa aos usos da escrita, inicialmente apresentada pelos autores referidos, não deve ser entendida em um sentido restrito, mas deve ser compreendida como válida para os usos da linguagem.

Nesse sentido, a prática letrada não é a mesma em todas as situações, pelo contrário, dependerá dos eventos que se configuram nos vários tipos de letramento. Se estamos imersos em uma sociedade cada vez mais dinâmica e complexa e, em consequência disso, temos a possibilidade de ter acesso a diferentes tipos de letramentos, há sujeitos, diríamos, não apenas letrados em uma dada agência, mas multiletrados. Isso favorece o surgimento de níveis de letramento - sujeitos mais letrados em certos letramentos em detrimento de outros, mas dificilmente iletrados.

Com isso, entendemos que a escola parece não ser mais a principal agência de letramento, mas outras agências como a midiática (cf LINO DE ARAÚJO, 2004), a religiosa e a familiar, por exemplo, vêm ganhando espaço socialmente e influenciando cada vez mais os sujeitos. Nesse sentido, os dados analisados por Silva (2009) sinalizaram que o atendimento às práticas requeridas pela prova de redação deu-se mais pelo contato que alguns candidatos tinham com o letramento literário, familiar, religioso e midiático do que com o escolar. Enquanto que o não atendimento a tais práticas, deu-se por candidatos que destacaram o letramento escolar como a principal fonte de contato.

Ratificamos que a escola não deixou de ser uma agência letrada, apenas parece-nos não ser mais a principal agência. Dessa forma, consideramos que todas as agências podem ser consideradas importantes, dependerá do contato que os sujeitos estabelecem com as práticas letradas exigidas pelos eventos dessas esferas; uma agência $\mathrm{x}$ de letramento pode ser fundamental para o sujeito A, ao passo que irrelevante para o sujeito B cuja agência que mais o influencia é a agência y.

O fato é que o contato com práticas letradas contribui para a constituição do HL dos sujeitos. Por isso, a importância de se conhecer esse HL antes de analisar determinadas práticas por si mesmas, descontextualizadas. O sujeito que escreve tem uma história da qual não se desprende no momento de escrever seu texto, pelo contrário, recorre, em geral, a ela para atender às exigências de determinados eventos de letramento.

Há várias pesquisas no campo do letramento crítico, em que pesquisadores têm sinalizado a influência de letramentos na história de vida de professores e de graduandos (cf. GUEDES-PINTO et all, 2005; SIGNORINI, 2005; COELHO, 2005; ALMEIDA, 2001; CAMPOS, 2001; GUEDES-PINTO, 2001). Outros pesquisadores têm demonstrado 
que o perfil sócio-econômico e cultural dos sujeitos influenciava-os na prática da leitura (cf. TERZI, 1995 e DELL'ISOLA, 1988) e na constituição de sua identidade (cf. RIBEIRO, 2005). Todas essas pesquisas ratificam que o ambiente sócio-cultural no qual o sujeito está inserido interfere na sua atuação seja enquanto aluno, seja enquanto professor, seja enquanto cidadão. Por isso, o conhecimento de sua história ajuda-nos a entender melhor suas posturas, comportamentos e crenças.

Neste sentido, as práticas de escrita parecem estar enraizadas no HL dos sujeitos, os quais se constituem tanto a partir do contato com os letramentos quanto devido ao seu perfil sócio-econômico e cultural; logo, parece haver uma relação entre este histórico e a produção textual. Entretanto, vale salientar que o HL não é elemento determinante das atitudes e comportamentos dos sujeitos, é, na verdade, um dos elementos que podem interferir nas práticas por eles demonstradas em eventos de letramento.

Nesta perspectiva e partindo do pressuposto de que as atitudes dos sujeitos parecem ser influenciadas pelo contexto sócio-cultural, conforme as normas que regem $\mathrm{o}(\mathrm{s})$ grupo(s) nos quais estão inseridos, defendemos, de igual maneira, que as práticas letradas demonstradas por eles resultam, em geral, do contato que estabelecem com determinada(s) agência(s) de letramento(s), a(s) qual(is) exige(m) determinadas posturas e comportamentos, além de considerarmos, é claro, as particularidades individuais.

Sob essa perspectiva, nossa proposta de pesquisa está pautada no pressuposto de que as práticas de uso da escrita são situadas socio e culturalmente, assumindo significados específicos em contextos, instituições e esferas sociais determinados.

\section{ANÁLISE}

Esta parte é constituída de duas seções. Na primeira, averiguamos as práticas letradas exigidas na produção da palestra; na segunda, correlacionamos as práticas demonstradas pelos candidatos (doravante $\mathrm{C} 1$ e $\mathrm{C} 2$ ) com seu HL.

\subsection{Práticas letradas requeridas na prova de redação}

Observando a prova de redação aplicada em 2007 no vestibular da UFCG, notamos, à semelhança das provas realizadas em 2005 e 2006 (cf. SILVA \& LINO DE ARAÚJO, 2006), a apresentação de uma proposta textual, na qual são indicados dois gêneros dos quais os candidatos deveriam escolher apenas um para produzir. Tendo-o escolhido, os vestibulandos deveriam atender a, pelo menos, três práticas letradas, a saber: participação no jogo enunciativo da prova (JEP), adequação do texto ao tema proposto e uso do registro escrito formal da língua portuguesa. Vejamos de que forma estas práticas são requeridas na prova: 
Exemplo 1

\section{REDAÇ̃̃o}

Escolha UMA das duas situações comunicativas apresentadas a seguir, e redija seu texto, com 20 linhas, no mínimo, e 25, no máximo.

\section{SITUAÇÃO I}

A Editora Globo reeditou o romance de Érico Veríssimo Clarissa. A revista Época, interessada pela temática desse romance, achou conveniente publicar uma resenha sobre ele. Como resenhista de veículos de comunicação escrita, escreva essa RESENHA, para ser publicada na revista semanal Época, que tem como leitores público jovem e adulto, com grau de escolaridade médio e superior.

\section{ATENÇÃO!!!}

RESENHA é entendida, nesta prova, como um gênero textual que apresenta, de forma sintética, uma obra (características, informações, forma...) acompanhada de uma avaliação, com o objetivo de oferecer informações que orientem o leitor sobre a leitura ou não dessa obra. O registro linguístico é o formal.

Para escrever sua resenha, inclua o resumo do enredo, comentários sobre a personagem central e sobre a ambientação em que a narrativa se desenvolve.

\section{SITUAÇÃO II}

Imagine-se como um profissional que teve dificuldade de escolher sua profissão e que deverá proferir uma PALESTRA, para um público formado por jovens e seus pais, sobre a escolha de um curso superior.

\section{ATENÇÃO!!!}

PALESTRA é entendida, nesta prova, como um gênero de texto que, mesmo sendo apresentado oralmente, é previamente escrito, desenvolvendo-se o tema proposto. A profundidade com que se explora o tema depende do público alvo e do tempo de que se dispõe. Escrito em registro formal, pode conter expositivas, argumentativas, narrativas e/ou descritivas.

Para auxiliá-lo a planejar sua palestra, releia os textos I e II. Não copie partes dos textos, sem que sejam indicadas as fontes e sem que elas fundamentem sua argumentação ou exposição.

(Prova de redação do vestibular especial UFCG 2007)

Podemos observar, na prova apresentada, uma relação intragênero, já que no interior do gênero "prova de redação", é solicitada a produção de outros gêneros, resenha e palestra. Nessa relação intragênero, os candidatos deparam-se com dois jogos enunciativos: o proposto pela prova - assumirem o papel social indicado nas instruções referentes ao gênero escolhido e escreverem para o locutor sinalizado - e outro escolar (JEE) - produzirem um texto com o objetivo de serem avaliados pela banca corretora do vestibular.

Esse JEP consiste no aceite da mudança de posição enunciativa - de vestibulando para a posição indicada na situação comunicativa proposta na prova. Ainda que o sujeito estivesse ocupando a posição enunciativa de candidato que deve escrever a redação com vistas a ser avaliado no tocante a uma vaga no ensino superior, JEE, deve, no momento da produção textual, assumir uma das posições enunciativas sugeridas nas propostas de redação. 
A noção de jogo enunciativo foi estudada também por Lino de Araújo (2004), quando analisou o telejornal Jornal Nacional, transmitido pela Rede Globo de televisão. Segundo a pesquisadora, os sujeitos responsáveis pela transmissão de informações não assumiam a posição enunciativa de repórteres - aqueles que estão preocupados com o simples repasse de notícias -, mas ocupavam, pelo menos, duas posições enunciativas diferentes, a saber: a de "defensores públicos", já que criticavam as ações governamentais e reclamavam quanto ao descaso por parte dos políticos, defendendo, assim, os cidadãos, e a de "professores", uma vez que instruíam/ensinavam os telespectadores sobre como poderiam economizar energia, pois estavam em período de racionamento.

Desse modo, assim como os repórteres assumem posições enunciativas diferentes como constitutivas do telejornal Jornal Nacional, fato que diferencia esse telejornal de outros, os candidatos ao vestibular da UFCG são incumbidos de assumir uma posição enunciativa que, provavelmente, não é a sua, como indício de que estão atendendo a uma das práticas letradas requisitadas pela prova, o que contribuirá para que obtenham êxito na redação.

O JEP é sinalizado no início das instruções dadas para a produção de cada gênero, no item SITUAÇÃO, pelo uso do verbo "imagine", cuja carga semântica aponta para uma escrita fundamentada numa criação, num convite para o candidato "esquecer" a sua posição enunciativa, vestibulando, e assumir outra, profissional que teve dificuldade de escolher sua profissão, no caso da produção da palestra, objeto de análise deste artigo. Tendo assumido a posição enunciativa indicada, o candidato deverá produzir a palestra para pais e filhos.

Os JEP são recorrentes nas provas de redação em que é solicitada a produção de um gênero textual, isso porque, embora sejam indicados o objetivo da produção, o público alvo e o ambiente de circulação do gênero, o destinatário é o corretor de redações de vestibular que as avalia com o objetivo de selecionar candidatos que almejam uma vaga no ensino superior.

Dessa forma, as situações comunicativas propostas na prova, assim como acontece normalmente na escola, não se concretizam efetivamente, mas servem para orientar a escrita dos candidatos, de modo que não pensem que a escrita é um dom (cf. SERCUNDES, 1998) e, portanto, que não é necessário conhecer o objetivo do texto nem o interlocutor alvo antes de escrever.

A inserção no JEP implica, além de adequar o texto às condições de produção, em respeitar a estrutura composicional do gênero, as quais foram, brevemente, descritas na prova no item ATENÇÃO!!!!

A palestra é um gênero de texto que, mesmo sendo apresentado oralmente, é previamente escrito, desenvolvendo-se o tema proposto. A profundidade com que se explora o tema depende do público alvo e do tempo de que se dispõe. Escrito em registro formal, pode conter expositivas, argumentativas, narrativas e/ou descritivas.

Em relação à segunda prática letrada requerida, adequação do texto ao tema indicado, os candidatos deveriam participar do JEP contemplando o seguinte tema: escolha profissional. Ainda que não tivessem conhecimento prévio do assunto, a contribuição temática foi oferecida na prova, uma vez que os textos apresentados na prova de língua 
portuguesa - "Como escolher a carreira certa" e um trecho do livro "Casa de Pensão"tratavam, direta ou indiretamente, do tema focalizado na redação.

Desse modo, os candidatos poderiam fazer referência, em suas produções, a esses textos, na condição de subsidiar a argumentação presente no gênero produzido, conforme orientação dada na prova - Não copie partes dos textos, sem que sejam indicadas as fontes e sem que elas fundamentem sua argumentação ou exposição. O oferecimento de contribuição temática é outro elemento que favorece a configuração do JEP, pois, mesmo sendo um contexto de seleção, em que a avaliação é pautada única e exclusivamente no produto, desconsiderando, portanto, a identidade e o HL dos candidatos, a banca elaboradora da prova apresenta uma proposta de redação pautada na concepção de escrita como processo. Uma das características dessa concepção é a de que para escrever é preciso ter o que dizer, sendo a intertextualidade um fator importante para tal, visto que contribui com a consistência argumentativa apresentada pelo sujeito, o qual poderá fazer, no seu texto, referências a outros textos, seja com o objetivo de concordar com as ideias expostas, seja com o de refutá-las.

Confirma-se, assim, o JEP, já que, embora a redação deva ser escrita com fins avaliativos, tem-se a preocupação de oferecer a todos os candidatos os elementos norteadores da produção textual em situações sócio-comunicativas reais - produção do gênero solicitado, articulando a estrutura composicional do mesmo às condições de produção dadas, assim como ao tema indicado.

Finalmente, a terceira prática letrada requerida na prova de redação diz respeito ao uso do registro escrito formal da língua portuguesa, tanto porque é característico do gênero solicitado, como por causa da exigência do concurso vestibular.

Vale salientar que, apesar de termos feito comentários sobre cada uma das práticas letradas requeridas pela prova de redação, o fizemos pela complexidade do objeto de investigação e por questões didáticas, haja vista que as consideramos imbricadas e interligadas. Por isso, a análise dos dados, que será apresentada no próximo item, está organizada em função da primeira prática letrada requerida pela prova de redação, JEP; as outras duas práticas (adequação do texto ao tema e o uso do registro escrito formal) encontram-se diluídas nesta.

\subsection{Práticas letradas correlacionadas com o HL}

Os candidatos que se inseriram no JEP referente à produção da palestra disseram que nunca haviam escrito o gênero, porém, ou já o haviam lido em Revistas, ou em casa (escrito por familiares), ou, ainda, assistido a palestras em agências letradas, a exemplo da midiática. Ilustraremos esse resultado com 2 exemplos retirados do corpus de Silva (2009). Vejamos a redação que segue. 
Exemplo 2

\author{
Caminho e escolhas: dúvidas persistentes ${ }^{3}$
}

Boa tarde, sou a coordenadora do curso de Medicina da universidade federal de campina Grande e fui escolhida para ministrar a palestra sobre escolha de profissão, por ter feito vários outros cursos antes de descobrir que a minha vocação era ser médica.

O primeiro fato que se deve ter em mente é que não importa qual será a sua profissão, você deverá estar sempre se atualizando para se destacar no mercado competitivo de trabalho. Não poderá parar de estudar.

Outro fator importante é que é permitido errar. A profissão escolhida este ano pode não ser daqui à duas décadas. Existem casos de pessoas com cinquênta, sessenta anos que descobrem que gostariam de seguir seus sonhos e começam a lutar por isso. Portanto, permita-se recomeçar sempre que perceber estar errados.

Agora que deixamos a pressão de lado, na escolha de um emprego o fundamental é gostar do que faz, assim, você jovem, antes de marcar aquele x na opção do curso, deve parar e refletir sobre as coisas que mais gosta de fazer e aquelas que não suporta. Quais matérias você gosta mais de estudar, com que área você se identifica mais.

Já aos pais cabe orientar os filhos sobre qual o melhor caminho a seguir e não impôr um caminho por pensarem ser o mais correto.

Assim, pensem sobre seus gostos e o que o deixaria mais feliz. Sigam seus corações pois este sim indicará o caminho certo.

(C1 - Redação produzida no vestibular especial UFCG 2007)

Podemos observar na redação exposta que $\mathrm{C} 1$ participou, de fato, do JEP, uma vez que, provavelmente considerando a organização das palestras com as quais disse já ter tido contato, escreveu a sua respeitando a estrutura composicional do gênero, bem como as condições de produção indicadas na prova - imaginar-se como uma pessoa experiente no tocante à escolha profissional e proferir uma palestra para pais e filhos quanto a esse assunto.

Tendo assumido o papel social de palestrante, inicia a palestra, conforme prática letrada exigida nesse evento: saudação inicial - boa tarde - seguida de sua apresentação pessoal - coordenadora do curso de Medicina da universidade federal de campina Grande - e do motivo pelo qual foi escolhida para proferir a palestra - fui escolhida para ministrar a palestra sobre escolha de profissão, por ter feito vários outros cursos antes de descobrir que a minha vocação era ser médica.

No segundo e no terceiro parágrafos, $\mathrm{C} 1$ apresenta duas ressalvas quanto à escolha profissional que são, respectivamente, (1) o indivíduo deverá sempre, independentemente do curso escolhido, atualizar-se e (2) é permitido errar na escolha da profissão, adequando sua fala ao tema indicado na prova, escolha profissional.

No quarto e no quinto parágrafos, o candidato direciona seu discurso para o público ao qual se destina a palestra, jovens e pais, confirmando, mais uma vez, sua inserção no JEP - ele não fez apenas uma exposição ou desenvolveu uma argumentação isolada/ descontextualizada, mas direcionou seu discurso para os supostos destinatários de sua palestra.

Ao se dirigir aos jovens, $\mathrm{C} 1 \mathrm{diz}$ :

\footnotetext{
${ }^{3}$ As redações foram transcritas tal como aparecem no corpus.
} 
Na escolha de um emprego o fundamental é gostar do que faz, assim, você jovem, antes de marcar aquele x na opção do curso, deve parar e refletir sobre as coisas que mais gosta de fazer e aquelas que não suporta. Quais matérias você gosta mais de estudar, com que área você se identifica mais.

O uso do pronome "você" marca, explicitamente, a tentativa do palestrante de interagir com os jovens, prática letrada requerida pelo evento de letramento aqui focalizado. Tendoos aconselhado, $\mathrm{C} 1$ dirige-se aos pais destes e pede a eles que orientem os filhos sobre qual o melhor caminho a seguir e não imponham um caminho por pensarem ser o mais correto. Tal conselho ratifica também a participação de C1 no JEP, dado que direciona sua fala para o público alvo indicado na prova e o aconselha quanto à forma pela qual deve lidar com a escolha profissional, tema proposto.

No último parágrafo, C1 finaliza sua palestra, dirigindo-se novamente aos jovens, aconselhando-os para que pensem sobre seus gostos e o que o deixaria mais feliz. Sigam seus corações pois este sim indicará o caminho certo. Observamos que o desfecho da palestra é marcado pela função conativa da linguagem, como sugere o uso dos verbos "pensem" e "sigam" que foram empregados no modo imperativo, evidenciando um convite, um apelo. Sendo um profissional experiente no assunto focalizado na palestra, como destacou no primeiro parágrafo, $\mathrm{C} 1$ conclui sua fala dando sugestões aos jovens no tocante à escolha profissional, outra prática letrada típica do evento palestra.

Entendemos que nossos comentários a respeito do ingresso de $\mathrm{C} 1$ no JEP podem ser respaldados pelo HL desse candidato. Desde pequeno, de acordo com a entrevista, disse que gostava muito de escrever desde textos relativamente informais como roteiros teatrais até textos técnicos como procurações para seu pai que é advogado. $\mathrm{O}$ ato de escrever para C1 parece ser cotidiano, heterogêneo e feito por prazer, sem ligação com as determinações escolares, até porque os gêneros por ele destacados dificilmente são abordados nessa instituição.

A nosso ver, essa familiaridade com a escrita permite o desenvolvimento das habilidades e competências de tal modalidade linguística, favorecendo a produção dos diversos textos com os quais o sujeito se depara, a exemplo da palestra, solicitada na prova de redação do vestibular. Ainda que nunca a tivesse escrito, C1 afirmou na entrevista que não sentiu dificuldades para produzi-la: eu nunca escrevi uma palestra, mas só que eu tinha noção. Eu já vi várias palestra, tendeu: Ai eu sabia como fazia (...) eu vi uma ou outra por escrito do meu pai e... só assistindo o resto (...) Meu pai costuma proferir palestra por causa do trabalho dele. $\mathrm{C} 1$ entende, assim, que o fato de nunca ter escrito uma palestra não o prejudicou na redação de vestibular, porque ele tinha noção do gênero e, sobretudo, assistiu a várias palestras, ou seja, parece que tinha um contato intenso com o gênero. A exposição a esse modelo de texto, na agência familiar e em outras agências de letramento não especificadas por $\mathrm{C} 1$, deve ter favorecido a apreensão das práticas letradas que regem tal evento. Essa apreensão de práticas pode ter sido realizada tanto a partir do contato com a escrita - leu palestras - quanto do comparecimento ao evento de letramento - assistiu a palestras.

Isso permite inferir a transposição de práticas letradas para a prova de redação. $\mathrm{C} 1$ talvez não tenha sentido dificuldades de fazer isso, visto que afirmou ser acostumado a escrever e já ter "noção" do gênero solicitado no vestibular, fatores que devem ter contribuído para que se sentisse confiante/seguro no momento de produzir a redação e, 
consequentemente, para que houvesse um enfraquecimento do efeito retroativo negativo do exame.

Além disso, afirmou que em casa sempre teve contato com a leitura e a escrita, pois seus pais liam e escreviam constantemente, sobretudo, por causa das suas atividades profissionais. Essa exposição às práticas familiares deve ter interferido também na constituição do HL de C1, bem como favorecido a sua inserção nesse meio, chegando, inclusive, a produzir procurações para seu pai, conforme afirmamos anteriormente.

Portanto, a inserção nesse meio letrado e o contato com o gênero palestra, em casa e em outras agências de letramento, parecem ter favorecido a participação de C1 no JEP.

Vale destacar ainda que o contato com as práticas letradas escolares parece não ter sido um dos fatores decisivos para que $\mathrm{C} 1$ atendesse às práticas requeridas pela prova de redação do vestibular. Isso porque, segundo ele, não estudou, na escola, como elaborar e/ ou proferir uma palestra, pelo contrário, seu desempenho na prova deu-se, provavelmente, pelo contato estabelecido com o gênero em outras agências letradas a exemplo da familiar.

Vejamos agora outro exemplo de uma palestra, a partir do qual procuramos correlacionar a participação no JEP com o HL do candidato.

\section{Exemplo 3}

O objetivo dessa palestra é auxiliar os jovens, aqui presentes, na escolha de suas profissões, esclarecendo como é que seus respectivos pais podem ajudá-los nesse processo.

Primeiramente, gostaria de aconselhar-los a não de deixarem influenciar pelo aspecto financeiro e até pelo status, porque fazer um curso só pelo seu prestígio deste no mercado de trabalho nunca foi garantia de sucesso, e esse desapego por sua profissão o tornará um profissional medíocre. O autor Aluísio de Azevedo, na sua obra "Casa de Pensão", retratou como a escolha errônea de seu personagem Amâncio refletiu negativamente em sua vida no trecho “...nunca daria um bom médico, que jamais teria amor à sua profissão".

Tomando novamente esse personagem como referência, não devemos deixar de levar em consideração nossas habilidades e dificuldades nas matérias que compõem o curso desejado. Se auto conhecendo vocês estarão aptos a escolherem qual será o caminho que devem trilhar. Como Amâncio ao perceber sua dificuldade para as matérias de cálculo descartou sua possibilidade de ir para a Marinha.

Além disso, os senhores pais devem ter em perspectiva que a função do pai é a de amparar o jovem emocionalmente durante a sua escolha, e não direcioná-lo para a profissão que os senhores acreditem ser melhor. Permitam que seus filhos possam escolher o seu próprio caminho. E finalmente, jovens sejam prudentes e calmos no momento da escolha, e boa sorte à todos.

(C2 - Redação produzida no vestibular especial UFCG 2007)

Como podemos verificar, C2 participa do JEP relativo à produção da palestra, demonstrando as práticas letradas requeridas por tal evento. No primeiro parágrafo, situa os leitores quanto ao objetivo da palestra - O objetivo dessa palestra é auxiliar os jovens, aqui presentes, na escolha de suas profissões, esclarecendo como é que seus respectivos pais podem ajudá-los nesse processo. Observamos que, além de apresentar o objetivo de sua fala, C2 interage com seu público alvo, conforme a expressão adverbial aqui presentes posposta à indicação de um dos interlocutores, jovens. Essa tentativa de interlocução com o destinatário é uma das práticas requeridas pela palestra, o que significa dizer que, ao demonstrá-la, C2 começa a inserir-se no JEP.

No segundo e no terceiro parágrafos, $\mathrm{C} 2$ aconselha os jovens quanto à escolha profissional, tomando como base argumentativa a escolha realizada por Amâncio, 
protagonista do romance "Casa de Pensão" escrito por Aluísio de Azevedo. Esse livro foi indicado na lista das obras literárias para o vestibular e um dos seus fragmentos foi apresentado na prova de língua portuguesa. C2 procurou relacionar o cerne de sua palestra com um dos temas focalizados no livro, a partir de referência intertextual. A nosso ver é uma estratégia produtiva, porque o candidato procura persuadir o público quanto ao tema indicado na prova, escolha profissional, explicitando a experiência do protagonista Amâncio, contada no romance. Para tal, alerta/aconselha os jovens, citando como Amâncio fez para escolher sua profissão, situação pela qual iriam passar: a escolha errônea de seu personagem Amâncio refletiu negativamente em sua vida; Tomando novamente esse personagem como referência, não devemos deixar de levar em consideração nossas habilidades e dificuldades nas matérias que compõem o curso desejado.

A referência, na redação, ao livro "Casa de Pensão" pode ser entendida como adequada aos dois públicos alvos da prova: os jovens, uma vez que $\mathrm{C} 2$, colocando-se na posição de palestrante, toma a experiência de vida de Amâncio como exemplo para ensinar aos ouvintes como proceder no tocante à escolha profissional; e a banca corretora das redações, pois o candidato, ciente de que estava concorrendo a uma vaga para ingressar no nível superior, procura sinalizar para a banca que leu o livro, articulando o enredo do mesmo ao tema e ao gênero indicados na prova de redação. C2 consegue, assim, participar do JEP e, ao mesmo tempo, parece querer mostrar para os corretores que cumpriu com uma das exigências do vestibular: ler as obras literárias indicadas para estudo, pelo menos, "Casa de pensão".

No último parágrafo, $\mathrm{C} 2$ dirige-se explicitamente aos senhores pais, aconselhandoos a amparar o jovem emocionalmente durante a sua escolha, e não direcioná-lo para a profissão que acreditem ser melhor. Permitam que seus filhos possam escolher o seu próprio caminho e aos jovens - sejam prudentes e calmos no momento da escolha, e boa sorte a todos. Finaliza sua palestra ratificando as recomendações feitas ao longo de sua fala e desejando sorte para os jovens, conforme prática letrada exigida pelo evento.

A correlação entre a inserção de C2 no JEP e seu HL é parecida com a apontada no caso de C1. À semelhança deste, aquele afirmou que nunca produzi, mas por já ter assistido várias palestras na televisão, mesmo não sendo sobre este tema, não vi dificuldade em escrever. Com isso, $\mathrm{C} 2$ destaca que a exposição intensa ao gênero, ainda que não tenha sido sobre o tema indicado na prova de redação, foi suficiente para que apreendesse as práticas letradas por ele requeridas e, assim, atualizasse-as no evento de letramento apresentado na prova.

Outro fator, atrelado à familiaridade com o gênero palestra, que deve ter influenciado C2 no momento da produção textual, foi seu hábito de escrever. Afirmou na entrevista: adoro escrever, sobretudo artigo de opinião. Escrevo quase todos os dias como forma de materializar meus pensamentos. Verifiquemos que $\mathrm{C} 2$, além de escrever quase diariamente, o fazia por prazer, como sugere o uso da expressão verbal "adoro escrever".

Possivelmente, a familiaridade com os gêneros argumentativos, indicada pelo candidato na entrevista, leva-nos a pensar que houve uma transposição de práticas letradas de um gênero, artigo de opinião, para outro, palestra. Notamos, de fato, na palestra, uma argumentação consistente e articulada; exemplificada e fundamentada em uma intertextualidade de natureza literária, como mostramos anteriormente. C2 consegue, 
assim, utilizar uma experiência ficcional, apresentada no romance "Casa de Pensão", como subsídio argumentativo utilizado em uma suposta situação real, a palestra.

Essa familiaridade com a escrita, bem como o hábito de escrever artigos devem ter influenciado a constituição do HL de $\mathrm{C} 2$, de forma a deixá-lo mais confiante no momento da prova de redação, reduzindo a interferência do efeito retroativo negativo do vestibular.

Nessa perspectiva, percebemos que a experiência com o gênero, associada ao hábito de escrever parecem ter contribuído para o bom desempenho dos candidatos na escrita da redação. Ademais, essa experiência, conforme $\mathrm{C} 2$ e semelhantemente a $\mathrm{C} 1$, parece não ter sido construída na agência escolar, mas no contato com outras agências letradas, no caso dele, com a familiar e a midiática.

Portanto, apesar de a palestra ser um gênero que dificilmente já foi produzido e/ou conferido pelos candidatos ao vestibular com faixa etária de dezesseis a dezoito anos, os entrevistados disseram conhecê-lo. Isso porque é um gênero, assim como a carta, disseminado nas diferentes agências de letramento - escolar, religiosa, familiar, midiática, entre outras.

Talvez tenha sido em virtude disso que $\mathrm{C} 1$ e C2 afirmaram não ter sentido dificuldades de produzi-lo, até porque, segundo eles, tinham sido expostos, várias vezes, a tal evento. Essa exposição, nos dois casos, fora do meio escolar, parece confirmar a evocação de outros letramentos como necessária para o cumprimento das práticas letradas exigidas pelas provas de redação.

No caso dos candidatos que participaram do JEE, Silva (2009) observou que eles produziram uma dissertação escolar em detrimento de uma palestra. Ao correlacionar as redações produzidas com o HL desses candidatos, a pesquisadora verificou que um dos principais fatores que devem tê-los influenciado a produzir a dissertação, conforme entrevista, foi a maior experiência com práticas letradas escolares frente às configuradas em outras agências. Esse resultado parece evidenciar que, se o contato com práticas de escrita estabelecido pelo candidato é restrito, ele tende a reproduzir na prova aquele gênero com o qual deve ter tido mais familiaridade e, talvez, segurança, para escrever, mas cujas sequências tipológicas predominantes aparecem, na maioria das vezes, no gênero solicitado.

\section{CONSIDERAÇÕES FINAIS}

Considerando os objetivos indicados no presente artigo, verificamos que, na prova de redação aplicada no vestibular da UFCG em 2007, foram exigidas três práticas letradas, a saber, participação no jogo enunciativo da prova, adequação do texto ao tema indicado e uso do registro escrito formal da língua portuguesa. A participação nesse jogo enunciativo requisitou dos candidatos familiaridade com letramentos e não apenas com o escolar, visto que a palestra é um gênero textual dificilmente abordado em livros didáticos e nos módulos de conteúdo, utilizados na escola, e raramente discutido ou ensinado nas aulas ministradas pelos professores de Língua Portuguesa/Redação.

Em virtude disso, aqueles que têm experiência com letramentos tendem a atender as práticas letradas requeridas na redação, ao passo que aqueles cuja experiência de escrita 
limita-se ao letramento escolar tendem a apresentar um desempenho pouco satisfatório, já que esse tipo de letramento parece não ser suficiente nem o único que pode ajudá-los a demonstrar as práticas exigidas na prova de redação, conforme evidenciado nos dados analisados por Silva (2009).

Ao que nos parece, $\mathrm{C} 1$ e $\mathrm{C} 2$ conseguiram participar do JEP porque têm um HL rico em práticas letradas - midiáticas e familiares. De modo que, ainda que nunca tivessem lido nem escrito uma palestra, tinham experiência com práticas letradas semelhantes às de tal evento, o que talvez tenha favorecido o processo de transposição de práticas de um evento para outro.

Assim sendo, os resultados aos quais Silva (2009) chegou sinalizam que apenas o letramento escolar parece não ser suficiente para que os candidatos atendam às práticas requeridas pela prova de redação, para que participem do JEP, o que não significa dizer que esse letramento seja desnecessário e irrelevante para aqueles que aspiram ingressar na UFCG. Na verdade, quando associado a outros letramentos, o escolar pode contribuir com a mobilização de práticas letradas de um evento para outro.

\section{REFERÊNCIAS BIBLIOGRÁFICAS}

ALMEIDA, A. L. (2001). O professor-leitor, sua identidade e sua práxis. In: KLEIMAN, A. (org.). A formação do professor. Campinas, São Paulo: Mercado de Letras, p. 115-135.

ANDRÉ, M. E. D. A. de. (1995). Fundamentos da pesquisa etnográfica. In: Etnografia da prática escolar. Campinas, São Paulo: Papirus, p. 15-69.

BARTON, D. e HAMILTON, M. (2000). Literacy Practices. In: BARTON, D.; HAMILTON, M. \& IVANIC, R. Situated Literacies. London e New York: Routledge, p. 07-15.

CAMPOS, S. (2001). A formação de uma professora sem terra: reflexos do processo na prática escolar. In: KLEIMAN, A. (org.). A formação do professor. Campinas, São Paulo: Mercado de Letras, p. 261-280.

COELHO, F. de C. B. (2005). O gênero textual entrevista como uma entre-vista. In: KLEIMAN, A. B. \& MATENCIO, M. de L. M. (orgs.). Letramento e formação do professor-práticas discursivas, representações e construção do saber. Campinas, SP: Mercado de Letras, (Coleção Idéias sobre Linguagem), p. 127-142.

COSTA VAL, M. da G. (1999). Redação e textualidade. São Paulo: Martins Fontes.

DELL'ISOLA, R. L. P. (1988). Leitura: inferências e contexto sócio-cultural. FALE - UFMG, Belo Horizonte.

GEE, J. P. (2000). The New literacy studies. In: Situated Literacies. Reading and Writing in Contex. London: Routeledge, p. 180-197.

GUEDES-PINTO, A. L. (2001). Narrativas de práticas de leitura: trajetórias da professora alfabetizadora. In: KLEIMAN, A. (org.). A formação do professor. Campinas, São Paulo: Mercado de Letras, p. 69-94. . et all. (2005). Percursos de letramento dos professores: narrativas em foco In: KLEIMAN, A. B. \& MATENCIO, M. de L. M. (orgs.). Letramento e formação do professor-práticas discursivas, representações e construção do saber. Campinas, SP: Mercado de Letras, (Coleção Idéias sobre Linguagem), p. 65-92.

HEATH, S. B. (1983). Ways with words: language, life and work in communities and classrooms.Cambridge: Cambridge University Press. 
Trab. Ling. Aplic., Campinas, 50(1), Jan./Jun. 2011

KLEIMAN, A. (2001). Formação do professor: retrospectivas e perspectivas na pesquisa. In: KLEIMAN, Ângela (org.). A formação do professor. Campinas, São Paulo: Mercado de Letras, p. 13-35.

LEMOS, C. T. G. de. (1984). Redações no vestibular: algumas estratégias. In: Cadernos de Pesquisa. Campinas, Unicamp - IEL, $\mathrm{n}^{\circ} 23$.

LIMBERTI, R. de C. A. P. (2006). "Herrar" é "umano": alguns aspectos da produção textual de vestibulandos. In: LARA, G. M. P. Língua (gem), texto e discurso - entre a reflexão e a prática. Rio de Janeiro: Lucerna; Belo Horizonte, Minhas Gerais: FALE/UFMG, p. 181-196.

LINO, D. de A. (2004). Um "professor" no horário nobre: estudo da explicação em telejornais. (Tese de Doutorado Inédita). São Paulo: USP, p. 128-135.

LOPES, I. de A. (2006). Cenas de letramentos sociais. Recife: Programa de Pós-Graduação em Letras da UFPB.

MARCUSCHI, L. A. (2001). Letramento e oralidade no contexto das práticas sociais e eventos comunicativos. In: SIGNORINI, Inês (org.). Investigando a relação oral/escrito. Campinas, São Paulo: Mercado de Letras, p. 23-50.

PÉCORA, A. (1986). Problemas de redação. São Paulo: Martins Fontes.

RIBEIRO, V. M. (2005). Uma perspectiva para o estudo do letramento - lições de um projeto em curso. In: KLEIMAN, A. B. \& MATENCIO, M. de L. M. (orgs.). Letramento e formação do professor - práticas discursivas, representações e construção do saber. Campinas, SP: Mercado de Letras, (Coleção Idéias sobre Linguagem), p. 17-40.

ROCCO, M. T. F. (1981). Crise na linguagem: a redação no vestibular. São Paulo: Mestre Jou.

SCRIBNER, S. \& COLE, M. (1981). The Psychology of Literacy. Cambridge: Havard University Press.

SERCUNDES, M. M. I. (1998). Ensinado a escrever. In: CHIAPPINI, Lígia \& GERALDI, João Wanderlei (orgs.). Aprender e ensinar com textos. v.1 São Paulo: Global, p. 21-39.

SIGNORINI, I. (2005). O relato autobiográfico na interação formador/formando. In: KLEIMAN, A. B. \& MATENCIO, M. de L. M. (orgs.). Letramento e formação do professor - práticas discursivas, representações e construção do saber. Campinas, SP: Mercado de Letras, (Coleção Idéias sobre Linguagem), p. 93-126.

SILVA, E. M. da S. \& LINO DE ARAÚJO, D. (2006). Redação e/ou gêneros textuais: caminhos de produção de textos no vestibular e no ensino médio. In: Anais da XXI Jornada Nacional de Estudos Linguísticos do Nordeste, João Pessoa, p. 35-43.

STREET, B. (1984). Literacy in theory and practice. Cambridge: Cambridge University Press, p. 1- 21.

TERZI, S. B. (1995). A oralidade e a construção da leitura por crianças de meios iletrados. In: KLEIMAN, A. Os significados do letramento. Campinas, São Paulo; Mercado de Letras, p. 91-117.

THEREZO, G. P. (2002). Como corrigir redação. Campinas, São Paulo: Alínea. 
DA SILVA e ARAÚJO - Mobilização de práticas letradas na produção...

VÓVIO, C. L. \& SOUZA, A. L. S. (2005). Desafios metodológicos em pesquisas sobre letramento. In: KLEIMAN, A. B. \& MATENCIO, M. de L. M. (orgs.). Letramento e formação do professor - práticas discursivas, representações e construção do saber. Campinas, SP: Mercado de Letras, (Coleção Idéias sobre Linguagem), p. 41-64.

Recebido: $17 / 05 / 2010$

Aceito: 18/05/2011 